\title{
IDENTIFIKASI FAKTOR PEMILIHAN PENYEDIA JASA FOTO KATALOG PRODUK (STUDI PADA PENGUSAHA ONLINE SHOP)
}

\author{
Widya Ayu Dyah Astuti \\ Universitas Negeri Surabaya \\ widyaastuti1@mhs.unesa.ac.id \\ Sanaji Sanaji \\ Universitas Negeri Surabaya \\ sanaji@unesa.ac.id
}

\begin{abstract}
This study aims to identify the factors considered by online shop owners in choosing photo catalogue services. This research is quantitative type. This study's data sources are primary data conducted by distributing questionnaires to research respondents. This research sample is 54 online shop owners who use product catalogue photo services. This research's variables are product attributes consisting of the brand, quality, features, design, price, and guarantee. The data collection technique uses questionnaires to 54 samples of product catalogue service users. In this case, the weighting questionnaire was filled in, done with Osgood's semantic differential measurement scale. This study's data analysis techniques were factor analysis, factor feasibility test, and correlation analysis. Are six factors to consider online businesspeople using product catalogue photo services. Product quality factors include high photo resolution, proper photo brightness; the resulting photo focuses on the product and colour match. The Feature Factor includes distinctive features, exceptional light-dark levels, and distinctive themes. Design factors include photo clarity, photo editing, and ready-to-upload photos. Factors include price according to quality, affordable prices, discounted prices, and price variations. The warranty factor includes product warranty items, a money-back guarantee, and a photo re-guarantee. Promotional factors that are informative, attractive promotions, promotions that are easy to remember, service readiness, problem-solving, services that are as promised and responsive to complaints.
\end{abstract}

Keywords: business buying; factors cosideration; photo product catalog; service provider selection,

\section{PENDAHULUAN}

Toko online banyak diminati para konsumen karena lebih praktis. Bagi para pemilik, toko online tidak memerlukan lapak fisik untuk menjual barangnya. Sementara itu, bagi para pembeli online dapat dengan mudah melihat alternatif barang serta harga yang akan dibeli. Kelebihan pembelian secara online yaitu proses belanja lebih praktis dan mudah dijalankan (Nurhayati, 2017). Berbagai cara dilakukan pemilik toko online kecil (reseller) untuk menarik pelanggan dengan produk-produk dagangnya secara online. Salah satu cara untuk menarik pelanggan agar membeli produk dagangannya yaitu dengan memakai jasa foto katalog untuk mengambil gambar produk dagangannya.

Katalog produk dalam dunia bisnis adalah suatu media yang berfungsi mempromosikan barangbarang yang dijual oleh suatu instansi untuk menarik calon pembeli (Halim, 2013). Melalui katalog produk sebagai media promosi, sebagaimana penjelasan Kotler dan Amstrong (2012:202) bahwa promosi merupakan penyebar informasi yang dapat memengaruhi konsumen agar membeli produk yang ditawarkan perusahaan.

Di et al. (2014) menyatakan bahwa gambar mampu mendorong transaksi dalam belanja online. Xin et al. (2014) juga menyatakan bahwa presentasi produk visual mampu memengaruhi perilaku belanja konsumen saat estetika visual disajikan lewat foto produk yang bisa ditangkap dengan bantuan teknik pemrosesan gambar modern. Namun, sebagian besar pemiliki toko online tidak memiliki pengetahuan yang baik tentang fotografi. Foto katalog produk yang dihasilkan tidak dapat memenuhi standar foto katalog produk yang baik.

Fenomena munculnya kebutuhan toko online terhadap foto katalog produk ini menyebabkan kehadirann bisnis jasa foto katalog produk. Usaha jasa pemotretan produk dagangan yang termasuk 
Widya Ayu Dyah Astuti \& Sanaji. Atribut-Atribut yang Menjadi Bahan Pertimbangan Pelanggan untuk Memilih Jasa Foto Katalog Produk (Studi pada Pengusaha Online Shop)

baru dalam dunia bisnis jasa foto ini mulai banyak dibutuhkan (Arum, 2015). Bisnis ini sangat dibutuhkan para pemilik toko online untuk menarik minat para pelanggan agar membeli produk dagang yang ditawarkan agar usahanya dapat bertahan di tengah persaingan. Semakin bagus suatu karya foto aliran ini, maka jumlah konsumen yang akan tertarik akan meningkat (Gunawan, 2014).

Hidayat et al. (2016) menyatakan bahwa jasa katalog produk memiliki teknologi multimedia sehingga mampu menciptakan katalog produk sebagai media promosi yang lebih efektif dan efisien dalam meningkatkan penjualan. Jasa foto katalog sudah menyediakan pelayanan seperti datang langsung ke tempat pelanggan untuk melakukan pemotretan produk-produk yang didagangkan serta menyediakan model, sehingga memudahkan pelanggan untuk menggunakan jasa fotonya. Pelanggan tidak perlu datang ke studio penyedia jasa katalog produk sehingga efisien dari sisi waktu dan biaya. Penyedia jasa foto katalog telah membangun reputasinya melalui hasil fotonya yang dapat menarik minat pelanggan. Putri et al. (2016) mengungkapkan bahwa foto-foto produk yang dihasilkan oleh jasa foto katalog produk berkualitas dan memiliki citra elegan dan mewah. Dari segi harga, dibandingkan dengan hasil foto yang dilakukan oleh pengusaha online shop sendiri, harga yang ditetapkan penyedia jasa foto katalog relatif terjangkau. Harga yang ditentukan sebanding dengan hasil fotonya. Jasa katalog dari segi pelayanan, citra merek, dan memiliki keunggulan, namun kenyataannya masih banyak toko-toko online yang memutuskan untuk tidak menggunakan jasa foto katalog dan lebih memilih untuk mengambil gambar produknya sendiri. Hal ini, mengindikasikan masih ada faktorfaktor lain yang menjadi pertimbangan pemilik toko online untuk mengambil suatu keputusan menggunakan atau tidak jasa foto katalog produk.

Maulana (2016) menyatakan bahwa untuk mendapatkan hasil pemasaran bisnis fotografi yang maksimum, proses pemasaran harus direncanakan melalui strategi pemasaran yang baik yang dilakukan dengan cara menguji situasi pemasaran saat ini, menyertakan peluang serta menentukan sasaran, dan mengembangkan strategi pemasaran. Sedangkan penelitian yang dilakukan oleh Prabowo dan Yulianeu (2017) membuktikan bahwa terdapat hal-hal yang dapat memengaruhi pelanggan dalam menggunakan jasa fotografi, yakni harga, kualitas, produk, kualitas pelayanan, serta kepercayaan. Sementara itu, Millan dan Bartrina (2013:307) menyatakan bahwa atribut terpenting dalam pemotretan produk adalah informasi tekstual yang meliputi nama, slogan, atau deskripsi merek.

Sampai saat ini, belum ada penelitian yang secara khusus mengidentifikasi atribut-atribut yang memengaruhi pemilik toko online dalam memilih jasa foto katalog. Selain karena jasa katalog produk merupakan jenis jasa yang masih relatif baru, penelitian sebelumnya belum ada yang membahas mengenai faktor-faktor yang memengaruhi pemilik toko online dalam memilih foto katalog. Dengan demikian perlu dilakukan penelitian tentang atribut-atribut yang memengaruhi pelanggan dalam memutuskan untuk menggunakan jasa foto katalog produk. Tujuan dari penelitian ini adalah untuk mengidentifikasi faktor-faktor yang dipertimbangkan pemiliki toko online dalam memilih penyedia jasa foto katalog produk.

\section{KAJIAN PUSTAKA}

\section{Teori Pembelian Bisnis}

Kotler dan Keller (2016:200) menyatakan pasar bisnis terdiri dari semua organisasi yang memperoleh barang dan jasa yang digunakan dalam produksi produk atau jasa lain yang dijual, disewakan, atau dipasok kepada orang lain. Perusahaan mana pun yang memasok komponen untuk produk berada di pasar bisnis-ke-bisnis. Beberapa industri utama yang membentuk pasar bisnis adalah dirgantara; pertanian, kehutanan, dan perikanan; bahan kimia; komputer; konstruksi; pertahanan; energi; pertambangan; manufaktur; konstruksi; angkutan; komunikasi; utilitas umum; perbankan, keuangan, dan asuransi; distribusi; dan layanan. Pembeli bisnis menghadapi banyak keputusan dalam melakukan pembelian. Berapa banyak tergantung pada kompleksitas masalah yang diselesaikan, kebutuhan pembelian yang baru, jumlah orang yang terlibat, dan waktu yang dibutuhkan. Tiga jenis situasi pembelian adalah pembelian ulang langsung, pembelian ulang yang dimodifikasi, dan tugas baru. Pembeli bisnis membuat keputusan paling sedikit dalam situasi pembelian kembali langsung dan paling banyak dalam situasi tugas baru. Seiring waktu, situasi pembelian baru menjadi perbaikan 
langsung dan perilaku pembelian rutin. Pembelian tugas baru adalah peluang dan tantangan terbesar pemasar (Kotler dan Keller, 2016: 643).

Proses pembelian melalui beberapa tahapan: kesadaran, minat, evaluasi, uji coba, dan adopsi. Media massa dapat menjadi media paling penting selama tahap kesadaran awal; staf penjualan sering kali memiliki pengaruh terbesar pada tahap minat; dan sumber teknis dapat menjadi yang paling penting selama evaluasi. Upaya penjualan online mungkin berguna di semua tahap. Dalam situasi tugas baru, pembeli harus menentukan spesifikasi produk, batas harga, persyaratan dan waktu pengiriman, persyaratan layanan, persyaratan pembayaran, jumlah pesanan, pemasok yang dapat diterima, dan pemasok yang dipilih (Kotler dan Keller, 2016: 214-215). Proses keputusan pembelian bisnis melibatkan delapan tahap dasar (Robinson, Faris, dan Wind dalam Kotler dan Amstrong, 2016:264), yakni (1) pengenalan masalah (problem recognition); (2) deskripsi kebutuhan umum (general need description); (3) spesifikasi produk (product specification); (4) pencarian pemasok (supplier search); (5) pengumpulan proposal (proposal solicitation); (6) pemilihan pemasok (supplier selection); (7) spesifikasi pesanan rutin (order routine specification); dan (8) tinjauan ulang kinerja (performance review).

\section{Faktor-Faktor yang Memengaruhi Pembelian Bisnis}

Salah satu atribut yang dipertimbangkan oleh pembeli dalam memutuskan pembelian produk adalah atribut produk. Simamora (2011) mendefinisikan atribut produk sebagai segala sesuatu yang melekat pada produk dan menjadi bagian dari produk itu sendiri. Menurut Tjiptono (2014), atribut produk merupakan unsur-unsur produk yang dianggap penting oleh konsumen dan dijadikan dasar pengambilan keputusan pembelian. Atribut produk terdiri dari merek, kualitas, fitur produk, desain produk, harga, dan jaminan. Merek adalah nama atau simbol yang dapat membedakan atau memudahkan dalam mengidentifikasi suatu produk barang/ jasa yang berupa logo, cap/ kemasan) (Aiker, 2014). Kualitas produk yaitu kemampuan suatu produk dalam memberikan kinerja sesuai dengan fungsinya (Bilgies, 2016). Sementara itu fitur produk merupakan sarana kompetitif yang digunakan untuk membedakan produk satu dengan produk-produk pesaing. Fitur produk identik dengan sifat dan sesuatu yang unik, khas dan istimewa yang tidak dimiliki oleh produk lainnya. Proses menciptakan produk baru yang akan dijual oleh perusahaan untuk pelanggannya (Kotler dan Amstrong, 2012: 273). Sedangkan harga merupakan nilai yang ditawarkan untuk menukar suatu produk. Jaminan adalah janji yang merupakan kewajiban produsen atas produknya kepada konsumen, di mana para konsumen akan diberi ganti rugi bila produk ternyata tidak bisa berfungsi sebagaimana yang diharapkan atau dijanjikan (Tjiptono, 2014:108). Selain atribut produk, faktor yang menjadi pertimbangan pembeli dalam memutuskan pembelian suatu produk adalah promosi dan pelayanan.

Faktor kualitas terdiri atas empat indikator yang diadaptasi dari teori fotografi (Soelarko, 2007:95), yakni resolusi foto, kecerahan foto, foto fokus produk, dan foto jelas dan terang. Faktor fitur mencakup tiga indikator yang mengadaptasi dari pendapat Soedjono (2006:211), yakni foto berciri khas, tingkat kegelapan, dan tema foto. Faktor desain meliputi edit foto, foto siap upload, dan warna foto yang diadaptasi dari Dameria (2007:121). Harga diadaptasi dari Stanton (2006:156) dan Mc Carthy, 2008:231) memiliki lima indikator yaitu harga sesuai kualitas, harga terjangkau, harga sesuai manfaat, diskon harga, dan harga bervariasi mengambil diadatasi. Faktor jaminan meliputi tiga indikator yakni garansi produk, garansi pengembalian uang, dan garansi foto ulang yang diadaptasi dari Kotler dan Keller (2016:230). Sementara faktor promosi terdiri atas tiga indikator, yakni promosi informatik, promosi menarik, dan promosi mudah diingat yang diperoleh dari pendapat Tjiptono (2015:110), sedangkan faktor kualitas pelayanan memiliki lima indikator yang diadaptasi dari Zeithaml (2000: 256) yaitu kesiapan pelayanan, kecepatan pelayanan, problem solving, pelayanan sesuai janji, dan responsif terhadap keluhan.

Kim et al. (2019) menyebutkan bahwa yang dapat menjadi faktor pembelian bisnis terdiri dari tiga aspek, yakni ekonomi, teknis, dan sosial. Aspek ekonomi terdiri dari harga, kualitas, pengiriman, fleksibilitas, kemampuan finansial, dan hubungan. Aspek teknis terdiri dari fasilitas fisik dan asset, 
Widya Ayu Dyah Astuti \& Sanaji. Atribut-Atribut yang Menjadi Bahan Pertimbangan Pelanggan untuk Memilih Jasa Foto Katalog Produk (Studi pada Pengusaha Online Shop)

kemampuan teknis, kemampuan memerkirakan, dan inovasi. Aspek sosial terdiri dari dukungan proyek komunitas, pengalaman mengatur krisis, donasi, dan pengaruh stakeholder.

Perusahaan berbasis teknologi, hal yang diperhatikan saat memilih pemasok adalah fungsionalitas, kepatuhan hukum, kontrak, geolokasi server, fleksibilitas, integrasi, transparansi kegiatan, sertifikasi, pemantauan, dukungan, control, model penyebaran, dan uji solusi (Lang et al., 2016). Penelitian yang dilakukan Park dan Krishnan (2001), yang memengaruhi suatu perusahaan dalam memilih supplier antara lain yaitu industri karakteristik personal, penjualan tahunan, usia eksekutif, jenis pendidikan, dan jenis pengalaman kerja.

Zhang et al. (2020) menyatakan bahwa sustainability yang terdiri dari kualitas pelayanan dan kemampuan pelayanan, penerapan teknologi informasi, dan gangguan polusi yang dihasilkan merupakan hal yang dipertimbangkan saat memilih supplier. Kant dan Dalvi (2015) menyebutkan bahwa kriteria memilih supplier antara lain yaitu pengiriman tepat waktu, kualitas kinerja, harga, reputasi/kinerja perusahaan, kemampuan teknis, fleksibilitas, kapasitas dan fasilitas produksi, pelayanan, posisi keuangan, harga bersih, lokasi geografis, responsive, komunikasi, kinerja lingkungan, standar kualitas, Percentage defectiveness in PPM, standar etis, lead time, kesopanan, tingkat kepuasan pelanggan, inovasi, dukungan pengembangan produk, kontrol operasi, loyalitas dan kepercayaan diri, dan kinerja produk. Cheraghi et al. (2011) menyatakan hal-hal yang perlu dipertimbangkan saat memilih supplier antara lain harga, kualitas, teknis, e-commerce, sejarah kinerja, pelayanan, kemampuan adaptasi, stabilitas keuangan, reliabilitas, ukuran, reputasi, fleksibilitas, tanggungjawab lingkungan, lead time, spesialisasi, pelayanan pelanggan, standar kualitas, komunikasi, tekologi, dan hubungan jangka panjang.

Ettenson dan Turner (1997) menyatakan bahwa yang diperhatikan perusahaan saat memilih suatu pelayanan adalah sumber informasi, lokasi, dan harga. infrastruktur, fleksibilitas. Yu et al. (2015) menyatakan bahwa yang diperhatikan saat akan menggunakan jasa suatu pelayanan adalah hard infrastructure yang terdiri dari tracing dan tracking, dan truk canggih, soft infrastructure yang terdiri dari IT, ketangkasan atau keahlian manusia, dan pengetahuan, dan fleksibilitas yang terdiri dari kedua macam infrastruktur tersebut (hard dan soft infrastructure). Casidy dan Nydzayo (2017), menyatakan bahwa hubungan jagka panjang dan situasi di bawah risiko tinggi adalah faktor yang memengaruhi pemilihan pelayanan.

\section{METODE PENELITIAN}

Jenis penelitian ini adalah kuantitatif. Penelitian ini merupakan penelitian exploratoris yang hendak mengidentifikasi faktor-faktor yang menjadi pertimbangan pebisnis online shop dalam menggunakan jasa foto katalog produk. Sumber data penelitian ini diperoleh dari sumber data primer data yang dihimpun oleh peneliti dari sumber pertama secara langsung. Sumber data primer penelitian ini yakni pengguna jasa foto katalog, dan sumber data sekunder yang berupa akun-akun instagram penyedia jasa foto katalog, daftar biaya yang dikeluarkan untuk menggunakan jasa foto katalog. Sampel penelitian ini adalah 54 pemilik toko online pengguna jasa foto katalog dengan kriteria minimal 2 kali menggunakan jasa foto katalog, terakhir kali menggunakan foto katalog ptoduk kurang dari satu bulan. Instrumen yang digunakan dalam penelitian ini berupa kuesioner (daftar pertanyaan tertutup) yaitu kuesioner dimana responden memberikan tanda terhadap alternatif jawaban yang dipilih. Teknik pengumpulan data penelitian ini dilakukan dengan menyebarkan kuesioner kepada 54 sampel pengguna jasa foto katalog.

Identifikasi faktor-faktor dalam penelitian ini terbagi menjadi dua tahap, yakni survei 1 yang dilakukan dengan identifikasi variabel-variabel yang dipertimbangkan dalam memilih penyedia jasa fotografi katalog produk. Survei ini dilakukan pada 30 responden melalui pertanyaan terbuka. Pada tahap ini faktor-faktor yang diajukan adalah kualitas, fitur, desain, harga, jaminan, dan merek. Faktor kualitas terdiri dari 4 indikator, yaknik resolusi foto, kecerahan foto, foto fokus produk, dan foto jelas dan terang. Kemudian faktor fitur terdiri dari 3 indikator, yakni foto berciri khas, tingkat kegelapan, dan tema foto. Sementara untuk faktor desain terdiri dari efit foto, foto siap diupload, dan warna foto. 
Sedangkan harga memiliki 5 indikator yaitu harga sesuai kualitas, harga terjangkau, harga sesuai manfaat, diskon harga, dan harga bervariasi. Lalu faktor jaminan terdiri dari 3 indikator yakni garansi produk, garansi pengembanlian uang, dan garansi foto ulang. Sementara faktor promosi terdiri dari 3 indikator, yakni promosi informatik, promosi menarik, dan promosi mudah diingat, sedangkanfaktor kualitas pelayanan memiliki lima indikator antara lain kesiapan pelayanan, kecepatan pelayanan, problem solving, pelayanan sesuai janji, dan responsive terhadap keluhan.

Untuk survei 2 dilakukan dengan melakukan survei atribut hasil dari survei 1. Faktor-faktor yang lolos pada survei 1 yaitu kualitas, fitur, desain, harga, dan jaminan. Sementara untuk faktor merek dieleminasi karena pada survei 1, merek tidak memiliki nilai terendah. Kemudian dari faktor-faktor tersebut disusun pertanyaan berskala likert dan dianalisis dengan analisis faktor. Dalam hal ini pengisian kuesioner pembobotan ini, dilakukan dengan skala pengukuran yang berbentuk semantic diferensial oleh Osgood. Teknik analisis adalah analisis faktor eksploratoris dengan Principal Component Analysis (PCA) yang bertujuan menemukan faktor. Setelah itu, kuesioner layak untuk digunakan dan kemudian dianalisis dengan analisis faktor, uji kelayakan faktor, dan analisis korelasi.

\section{HASIL DAN PEMBAHASAN}

Data penelitian ini didapatkan dari kuesioner yang telah diisi oleh responden melalui google form. Sesudah terkumpul terdapat 54 responden dilakukan verifikasi. Setelah dinyatakan semua kuesioner lengkap kemudian dilakukan pengolahan data dan penyajian hasil olah data.

\section{Karakteristik responden}

Karakteristik responden penelitian ini meliputi jenis kelamin, usia, pendidikan, dan bidang usaha responden. Mayoritas responden adalah perempuan $(81,5 \%)$, disusul dengan responden laki-laki $(18,5 \%)$. Menurut usianya mayoritas responden berusia 18-25 tahun $(48,1 \%)$, disusul dengan responden dengan usia 26-35 tahun (42,6\%), kemudian responden yang berusia antara 36-45 tahun $(7,4 \%)$, dan terakhir yaitu responden dengan usia $>45$ tahun $(1,9 \%)$. Pendidikan responden sebagian besar D3-S1 (70,4\%), kemudian responden dengan pendidikan terakhir SMA/SMK (25,9\%), dan terakhir yaitu responden dengan pendidikan S2-S3 (3,7\%). Bidang usaha yang dijalankan oleh responden sebagian besar adalah kuliner $(42,6 \%)$, kemudian disusul oleh bidang usaha fashion $(40,7 \%)$, lalu kecantikan $(3,7 \%)$, selanjutnya bidang pulsa, bidang rempah, bidang, pendidikan, bidang tanaman, bidang rental, dan bidang dekorasi masing-masing sebesar 1,9\%.

\section{Statistik deskriptif}

Berikut ini hasil statistik deskriptif hasil olah data jawaban responden atas kuesioner

\section{Tabel 1 \\ STATISTIK DESKRIPTIF}

\begin{tabular}{llllc}
\hline No & Faktor apriori & \multicolumn{1}{c}{ Variabel/Indikator } & Simbol & Rata-rata \\
\hline 1 & Kualitas & a. Resolusi foto & a. X1.1 & 6,96 \\
& & b. Kecerahan foto & b. X1.2 & 6,52 \\
& & c. Foto fokus produk & c. X1.3 & 6,80 \\
2 & \multirow{4}{*}{ Fitur } & d. Foto jelas dan terang & d. X1.4 & 6,76 \\
& & a. Foto berciri khas & a. X2.1 & 6,24 \\
& & b. Tingkat kegelapan & b. X2.2 & 7,00 \\
3 & Desain & c. Tema foto & c. X2.3 & 6,90 \\
& & a. Edit foto & a. X3.1 & 6,96 \\
& b. Foto siap diupload & b. X3.2 & 6,86 \\
4 & Harga & c. Warna foto & c. X3.3 & 6,74 \\
& & a. Harga sesuai kualitas & a. X4.1 & 6,54 \\
& & b. Harga terjangkau & b. X4.2 & 6,68 \\
& c. Harga sesuai manfaat & c. X4.3 & 6,06 \\
& & d. Diskon harga & d. X4.4 & 6,78 \\
& & e. Harga bervariasi & e. X4.5 & 6,58
\end{tabular}


Widya Ayu Dyah Astuti \& Sanaji. Atribut-Atribut yang Menjadi Bahan Pertimbangan Pelanggan untuk Memilih Jasa Foto Katalog Produk (Studi pada Pengusaha Online Shop)

\begin{tabular}{llllc}
\hline No & Faktor apriori & \multicolumn{1}{c}{ Variabel/Indikator } & Simbol & Rata-rata \\
\hline 5 & Jaminan & a. Garansi produk & a. X5.1 & 6,22 \\
& & b. Garansi pengembalian uang & b. X5.2 & 6,22 \\
6 & \multirow{2}{*}{ Promosi } & c. Garansi foto ulang & c. X5.3 & 6,46 \\
& & a. Promosi informatik & a. X6.1 & 6,52 \\
& & b. Promosi menarik & b. X6.2 & 6,74 \\
7 & Kualitas & c. Promosi mudah diingat & c. X6.3 & 6,56 \\
& Pelayanan & a. Kesiapan pelayanan & a. X7.1 & 6,68 \\
& & b. Kecepatan pelayanan & b. X7.2 & 6,72 \\
& c. Problem solving & c. X7.3 & 6,78 \\
& d. Pelayanan sesuai janji & d. X7.4 & 6,88 \\
& & e. Responsif terhadap keluhan & e. X7.5 & 6,76 \\
\hline
\end{tabular}

Sumber : Hasil Olah Data SPSS

$\begin{array}{lll}\text { e. Responsif terhadap keluhan } & \text { e. X7.5 } 6,76\end{array}$

Nilai rata-rata jawaban kuesioner responden diperoleh dari total skor dibagi jumlah responden dalam penelitian ini. Rata-rata nilai semua indikator menunjukkan di atas 6. Hal ini berarti bahwa sebagian besar responden menyatakan bahwa seluruh indikator dalam penelitian ini dianggap sangat penting.

\section{Uji Kelayakan Analisis Faktor}

Untuk meringkas variabel menjadi faktor-faktor, pada penelitian ini digunakan metode ekstraksi principle component analysis (PCA) rotasi varimax. Hasil analisis faktor perlu diuji kelayakannya, agar dapat diinterpretasi. Untuk menguji kelayakan analisis faktor digunakan kriteria kecukupan sampel KMO, signifikansi Barlettt's test, dan Total Variance Explained, seperti disajikan pada tabel 2.

Tabel 2

KELAYAKAN MODEL

\begin{tabular}{|c|c|c|}
\hline Keterangan & Hasil & Hasil \\
\hline Kaiser-Meyer-Olkin & 0,749 & Layak / tepat \\
\hline \multicolumn{3}{|l|}{ Measure of Sampling Adequacy } \\
\hline Bartlett test of sphericity & 235; Sig. $=0,000$ & Layak / tepat \\
\hline Total Variance Explained & $74,601 \%$ & Baik \\
\hline Jumlah factor & 26 & \\
\hline
\end{tabular}

Sumber: Hasil Olah Data SPSS

Berdasarkan hasil uji terhadap kelayakan penggunaan analisis faktor untuk memecahkan masalah penelitian, maka tabel 2 dapat dijelaskan sebagai berikut: Kaiser-Meyer-Olkin (KMO) Measure of Sampling Adequacy = 0,749; bahwa penggunaan analisis faktor sudah benar. Bartlett test of sphericity $=235$ dengan signifikansi $0,000<0,05$ berarti bahwa penggunaan analisis faktor sudah tepat untuk digunakan mereduksi data. Varian kumulatif $=30,457 \%$ dari total varian variabel awal, yang berarti bahwa $67,5 \%$ varian dalam data terwakili. Varian kumulatif $=30,457 \%$ menunjukkan bahwa penggunaan analisis faktor sudah baik. Dengan menggunakan ekstraksi PCA dan rotasi varimax, diperoleh jumlah faktor 6 dengan varian kumulatif 74,601\%

\section{Faktor-faktor yang dihasilkan}

Untuk mengetahui faktor-faktor yang dihasilkan dapat dilihat pada tabel berikut ini :

Tabel 3

FAKTOR-FAKTOR YANG DIHASILKAN

\begin{tabular}{cllccc}
\hline Faktor & \multicolumn{1}{c}{ Variabel } & Loading factor & \% Varian & Nama faktor \\
\hline Faktor 1 & X1.1 & Resolusi foto & 0,701 & 22,294 & Kualitas \\
& X1.2 & Kecerahan foto & 0,759 & & Produk \\
& X1.3 & Foto fokus produk & 0,666 & & \\
Faktor 2 & X1.4 & Warna foto & 0,684 & & Fitur \\
& X2.1 & Foto jelas dan terang & 0,559 & 12,685 & \\
& X2.2 & Edit foto & 0,666 & &
\end{tabular}




\begin{tabular}{|c|c|c|c|c|c|}
\hline Faktor & & Variabel & Loading factor & $\%$ Varian & Nama faktor \\
\hline \multirow[t]{3}{*}{ Faktor 3} & $\mathrm{X} 3.1$ & Ciri khas foto & 0,883 & 10,912 & Desain \\
\hline & $\mathrm{X} 3.2$ & Kegelapan foto & 0,870 & & \\
\hline & $\mathrm{X} 3.3$ & Tema foto & 0,602 & & \\
\hline \multirow[t]{5}{*}{ Faktor 4} & $\mathrm{X} 4.1$ & Harga sesuai kualitas & 0,735 & 10,187 & Harga \\
\hline & $\mathrm{X} 4.2$ & Harga terjangkau & 0,696 & & \\
\hline & $\mathrm{X} 4.3$ & Harga sesuai manfaat & 0,654 & & \\
\hline & $\mathrm{X} 4.4$ & Diskon harga & 0,701 & & \\
\hline & $\mathrm{X} 4.5$ & Harga bervariasi & 0,861 & & \\
\hline \multirow[t]{3}{*}{ Faktor 5} & X5.1 & Garansi produk & 0,867 & 9,293 & Jaminan \\
\hline & $\mathrm{X} 5.2$ & Garansi penegmbalian uang & 0,911 & & \\
\hline & $\mathrm{X} 5.3$ & Garansi foto ulang & 0,867 & & \\
\hline \multirow[t]{7}{*}{ Faktor 6} & X6.1 & Promosi informative & 0,775 & 9,230 & Promosi \\
\hline & X6.2 & Promosi menarik & 0,745 & & \\
\hline & X6.3 & Promosi mudah diingat & 0,823 & & \\
\hline & X6.4 & Kesiapan pelayanan & 0,775 & & \\
\hline & X6.6 & Problem solving & 0,895 & & \\
\hline & X6.7 & Pelayanan sesuai janji & 0,829 & & \\
\hline & X6.8 & Responsif terhadap keluhan & 0,638 & & \\
\hline
\end{tabular}

Sumber: Hasil Olah Data SPSS (2020)

\section{Peranan Indikator dalam Menentukan Faktor}

Kemampuan indikator dalam menjelaskan faktor dapat dilihat dari nilai faktor loading Menurut Santoso (2015), semakin besar nilai faktor loading maka semakin tinggi peranan indikator dalam menjelaskan faktor yang terbentuk.

Distribusi 26 indikator pada keenam faktor yang terbentuk dapat dilihat pada tabel 3. Angka-angka pada tabel tersebut menunjukkan besarnya varian dari indikator yang mampu dijelaskan oleh faktor yang terbentuk. Contohnya indikator resolusi foto memiliki korelasi sebesar 70,1\% terhadap faktor yang terbentuk, demikian seterusnya.

Proses pembentukan faktor oleh indikator pembentuknya dapat dilihat dari hasil uji Rotated Component Matrix. Sebuah indikator dinyatakan berperan sebagai pembentuk faktor ditunjukkan oleh nilai loading factor tertinggi. Hasil penelitian menunjukkan bahwa indikator resolusi foto, kecerahan foto, foto fokus produk, dan warna foto mempunyai nilai loading factor tertinggi dalam membentuk faktor 1. Indikator foto berciri khas, tingkat kegelapan, dan tema foto mempunyai nilai loading factor tertinggi dalam membentuk faktor 2. Indikator foto jelas dan terang, edit foto, dan foto siap diupload mempunyai nilai loading factor tertinggi dalam membentuk faktor 3. Indikator harga sesuai kualitas, harga terjangkau, harga sesuai manfaat, diskon harga, dan harga bervariasi mempunyai nilai loading factor tertinggi dalam membentuk faktor 4. Indikator garansi produk, garansi pengembalian uang, dan garansi foto ulang mempunyai nilai loading factor tertinggi dalam membentuk faktor 5. Indikator promosi informatif, promosi menarik, promosi mudah diingat, kesiapan pelayanan, kecapatan pelayanan, problem solving, pelayanan sesuai janji, dan responsif terhadap keluhan mempunyai nilai loading factor tertinggi dalam membentuk faktor 6. Selengkapnya perhatikan tabel 3.

Merujuk pada hasil analisis faktor eksploratori, terdapat faktor-faktor yang menjadi pertimbangan pengusaha online dalam memutuskan menggunakan foto katalog produk. Faktor-faktor tersebut terbentuk setelah melalui beberapa tahapan yaitu menentukan jumlah faktor menjadi 6. Berikut ini jumlah faktor yang menjadi pertimbangan pengusaha online dalam memutuskan menggunakan foto katalog produk.

\section{Faktor 1: Kualitas Produk}

Faktor 1 diberi nama faktor kualitas produk, terdiri dari 4 indikator, meliputi item pertanyaan resolusi foto yang tinggi, kecerahan foto yang tepat, foto yang dihasilkan fokus pada produk, dan warna yang serasi. Seluruh item pembentuk faktor tersebut membuktikan bahwa resolusi foto, kecerahan foto, fokus foto, dan warna foto menjadi bahan pertimbangan pebisnis online untuk menggunakan jasa foto 
Widya Ayu Dyah Astuti \& Sanaji. Atribut-Atribut yang Menjadi Bahan Pertimbangan Pelanggan untuk Memilih Jasa Foto Katalog Produk (Studi pada Pengusaha Online Shop)

katalog produk. Faktor kualitas produk menjelaskan 22,294\% terhadap data asli. Indikator kecerahan foto memberi kotribusi terbesar dalam membentuk faktor kualitas produk, yang ditunjukkan oleh loading factor sebesar 0,759 .

Faktor 2 : Fitur Produk

Faktor 2 diberi nama faktor fitur yang meliputi foto katalog yang mempunyai ciri khas, tingkat teranggelap yang khas, dan tema yang khas. Semua item pembentuk faktor tersebut membuktikan bahwa foto katalog yang mempunyai ciri khas, tingkat terang-gelap yang khas, dan tema yang khas menjadi bahan pertimbangan pebisnis online untuk menggunakan jasa foto katalog produk. Faktor fitur, menjelaskan $12,685 \%$ terhadap data asli. Indikator edit foto memberi kotribusi terbesar dalam membentuk faktor fitur, yang ditunjukkan oleh loading factor sebesar 0,666.

Faktor 3 : Desain

Faktor 3 diberi nama desain mencakup item kejelasan foto, edit foto, dan foto siap upload. Seluruh item pembentuk faktor tersebut membuktikan bahwa foto katalog yang mempunyai kejelasan foto, edit foto, dan foto siap upload menjadi bahan pertimbangan pebisnis online untuk menggunakan jasa foto katalog produk Faktor desain, menjelaskan 10,912\% terhadap data asli. Indikator ciri khas foto memberi kotribusi terbesar dalam membentuk faktor desain, yang ditunjukkan oleh loading factor sebesar 0,883 .

Faktor 4 : Faktor Harga

Faktor 4 diberi nama harga terdiri atas item harga sesuai kualitas, harga yang terjangkau, potongan harga, dan varasi harga. Seluruh item pembentuk faktor tersebut membutikan bahwa foto katalog yang mempunyai item harga sesuai kualitas, harga yang terjangkau, potongan harga, dan variasi harga menjadi bahan pertimbangan pebisnis online untuk menggunakan jasa foto katalog produk. Faktor desain, menjelaskan 10,187\% terhadap data asli. Indikator harga bervariasi memberi kotribusi terbesar dalam membentuk faktor harga, yang ditunjukkan oleh loading factor sebesar 0,861.

Faktor 5: Faktor Jaminan

Faktor 5 diberi nama jaminan meliputi item garansi produk, garansi pengembalian uang, dan garansi foto ulang. Seluruh item pembentuk faktor tersebut membutikan bahwa foto katalog yang mempunyai item garansi produk, garansi pengembalian uang, dan garansi foto ulang menjadi bahan pertimbangan pebisnis online untuk menggunakan jasa foto katalog produk. Faktor jaminan, menjelaskan 9,293\% terhadap data asli. Indikator garansi pengembalian uang memberi kotribusi terbesar dalam membentuk faktor jaminan, yang ditunjukkan oleh loading factor sebesar 0,911.

Faktor 6: Faktor Promosi

Faktor 6 diberi nama promosi meliputi item promosi yang informastif, promosi menarik, promosi yang mudah diingat, kesiapan pelayanan, problem solving, pelayanan yang sesuai dengan yang dijanjikan serta tanggap terhadap keluhan konsumen. Seluruh item pembentuk faktor tersebut membutikan bahwa promosi yang informastif, promosi menarik, promosi yang mudah diingat, kesiapan pelayanan, problem solving, pelayanan yang sesuai dengan yang dijanjikan serta tanggap terhadap keluhan konsumen menjadi bahan pertimbangan pebisnis online untuk menggunakan jasa foto katalog produk. Faktor Promosi, menjelaskan 9,230\% terhadap data asli. Indikator problem solving memberi kotribusi terbesar dalam membentuk faktor harga, yang ditunjukkan oleh loading factor sebesar 0,895

\section{Faktor-Faktor yang Memengaruhi Pembelian Bisnis}

Sesuai dengan hasil penelitian dapat diketahui bahwa dari 26 varaibel yang menjadi pertimbangan pengusaha online dalam memutuskan penggunaan jasa foto katalog produk dapat terbentuk menjadi enam faktor. Faktor tersebut meliputi faktor kualitas prosuk, faktor fitur, faktor desain, faktor harga, faktor jaminan, dan faktor promosi. Faktor-faktor yang terbentuk dan menjadi menjadi bahan pertimbangan pebisnis dalam memutuskan penggunaan suatu jasa tersebut sejalan dengan hasil penelitian yang dilakukan oleh Yulianeu (2017). Penelitian tersebut membuktikan bahwa terdapat hal- 
hal yang dapat memengaruhi pelanggan dalam menggunakan jasa fotografi, yakni harga, kualitas, produk, kualitas pelayanan, serta kepercayaan.

Berdasarkan persentase variance extracted, faktor yang terbesar yang menjadi pertimbangan dan memutuskan penggunaan jasa foto katalog produk adalah faktor promosi yang meliputi variabel item promosi yang informatif, promosi menarik, promosi yang mudah diingat, kesiapan pelayanan, problem solving, pelayanan yang sesuai dengan yang dijanjikan serta tanggap terhadap keluhan kosnumen sebab promosi merupakan awal dari ketertarikan pebisnis menggunakan jasa.

Kualitas foto adalah hal penting sebab kualitas foto katalog produk dapat mendorong konsumen tertarik dengan produk (Xin et al., 2016). Kualitas foto dapat diperhatikan melalui pengamatan langsung terhadap fisik foto. Pebisnis online akan menggunakan jasa foto katalog produk jika foto yang dihasilkan memiliki resolusi tinggi, kecerahan, fokus pada produk, dan warna foto yang tajam. Kualitas foto terutama foto katalog produk untuk pebisnis online akan membantu menarik minat beli konsumen (Xin et al., 2016). Sebagaimana dalam penelitian Di et al. (2014) yang meneliti tentang peran gambar (foto) dalam e-commerce menyatakan bahwa gambar (foto) atau informasi multimedia lainnya mambu mendorong peningkatan transaksi belanja online.

Usaha online baik di bidang kuliner, fashion, atau jasa sangat banyak, sehingga membutuhkan pembeda agar dikenal oleh konsumen. Salah satu cara untuk membuat perbedaan dengan kompetitor adalah foto katalog yang khas. Oleh karena itu, pebisnis perlu mencari foto katalog yang memiliki fitur foto katalog yang memiliki ciri khas. Bisnis online di berbagai bidang baik barang ataupun jasa harus memiliki daya tarik yang kuat agar calon konsumen mau mencoba menggunakan produk yang ditawarkan. Desain foto katalog produk yang bagus merupakan faktor penting dalam upaya menawarkan suatu produk online kepada konsumen. Foto yang dihasilkan harus memiliki unsur kejelasan foto, edit foto yang rapi, dan foto siap upload ke media apapun.

Harga juga merupakan komponen yang sensitif bagi pengguna jasa katalog produk. Harga yang sesuai dengan harapan pengguna jasa akan cenderung untuk digunakan produknya. Menurut Setiadi (2010:331) harga yang kompetitif akan memengaruhi konsumen untuk memilih produk atau jasa yang ditawarkan daripada produk yang ada di pasaran lainnya. Semakin sesuai harga dengan manfaat yang diterima konsumen, maka semakin tinggi keputusan pembeliannya.

Jaminan akan membuat pengusaha merasa aman bila terjadi kesalahan dapat proses produksi foto terjadi kesalahan yang mengakibatkan foto rusak atau tidak sesuai yang diinginkan. Adanya jaminan dapat mengurangi risiko yang akan ditanggung oleh pebisnis online saat memesan jasa katalog produk. Foto yang ditawarkan ke pebisnis online harus memenuhi aspek garansi produk, garansi pengembalian uang, dan garansi foto ulang.

Promosi yang informatif, menarik, mudah diingat, memberikan pelayanan yang baik akan mendorong pebisnis menggunakan jasa foto katalog produk (Hidayat et al., 2016). Faktor promosi yang gencar dan menarik baik secara konten maupun kemasan yang disukung oleh pelayanan yang prima akan menjadi pertimbangan bagi pengusaha online shop dalam menggunakan jasa foto katalog produk.

\section{KESIMPULAN}

Terbentuk enam faktor yang menjadi bahan pertimbangan konsumen bisnis online shop dalam menggunakan jasa foto katalog produk yaitu: faktor kualitas produk yang meliputi resolusi foto yang tinggi, kecerahan foto, fokus foto, dan warna yang serasi. Faktor Fitur mencakup ciri khas foto, tingkat terang-gelap yang khas, dan tema yang khas. Faktor desain meliputi kejelasan foto, edit foto, dan foto siap upload. Faktor harga mencakup kesesuaian harga dan kualitas, harga yang terjangkau, diskon, dan varasi harga. Faktor jaminan meliputi garansi produk, garansi pengembalian uang, dan garansi foto ulang. Faktor promosi meliputi promosi yang informastif, promosi yang menarik, 
Widya Ayu Dyah Astuti \& Sanaji. Atribut-Atribut yang Menjadi Bahan Pertimbangan Pelanggan untuk Memilih Jasa Foto Katalog Produk (Studi pada Pengusaha Online Shop)

promosi yang mudah diingat, kesiapan pelayanan, problem solving, pelayanan yang sesuai dengan yang dijanjikan serta tanggap terhadap keluhan.

Hasil penelitian ini yang dapat dijadikan sebagai bahan rujukan agar pebisnis foto katalog produk memerhatikan faktor kualitas produk, faktor fitur, faktor desain, faktor harga, faktor jaminan, dan faktor promosi agar jasanya digunakan oleh pebisnis online. Keenam faktor tersebut merupakan faktor yang menjadi pertimbangan pebisnis online untuk memutuskan apakah menggunakan jasa foto katalog produk atau tidak. Bagi peneliti berikutnya diharapkan mampu mengembangkan jumlah item dan aspek yang menjadi pertimbangan perusahaan online dalam memutuskan penggunaan jasa katalog produk.

\section{DAFTAR PUSTAKA}

Aaker, D. (2014). Building Strong Brands. (A. Baderi, Trans.) Jakarta: Bumi Aksara

Arum, N.S. (2015). Bisnis Jasa Foto Produk: Pemain Ramai, Daun Hitam Photography Andalkan Harga Promosi. (https://entrepreneur.bisnis.com/read/20151120/263/494087/bisnis-jasa-fotoproduk-pemain-ramai-daun-hitam-photography-andalkan-harga-promosi, diakses pada tanggal 18 November 2019).

Casidy, R., \& Nydzayo, M. (2017). Drivers and Outcomes of Relationship Quality with Professional Service Firms: An SME Owner-Manager Perspective. Industrial Marketing Management, $78(10)$.

Cheraghi, S. H., Dadashzadeh, M., Subramanian, M. (2011). Critical Success Factors For Supplier Selection: An Update. Journal of Applied Business Research, 20(2).

Dameria, A. (2007). Color Basic : Panduan Dasar Warna untuk Desainer dan Industri Grafika. Jakarta: Link Match Graphic.

Di, W., Sundaresen, N., Piramuthu, R., Bhardwaj, A. (2014). Is a Picture Really Worth a Thousand Words? - On the Role of Images in E-commerce. Proceedings of the 7th ACM international conference. 633-642.

Ettenson, R., \& Turner, K. (1997). An Exploratory Investigation of Consumer Decision Making for Selected Professional and Nonprofessional Services. The Journal of Services Marketing, 11(2).

Gunawan, A.P. (2014). Genre Fotografi yang Diminati oleh Fotografer di Indonesia. Humaniora. 5(2): 1234-1245.

Halim, R. (2013). Pembuatan E-katalog dan E-lelang pada Sistem Android. Calyptra: Jurnal Ilmiah Mahasiswa Universitas Surabaya, 2(1), 1-10.

Hidayat, W., Mahmuriyah, R., \& Safitri, S. N. R. (2016). Media Visual Berbentuk Katalog Produk Sebagai Media Promosi. Journal SENSI-Strategic of Education in Information System, 2(2), 184-197.

Kant, R., \& Dalvi, M. V. (2015). Development of Questionnaire to Assess the Supplier Evaluation Criteria and Supplier Selection Benefits. Benchmarking an International Journal, 24(2): 259383..

Kim, S., Ramkumar, M., \& Subramanian, N. (2019). Logistics Service Provider Selection for Disaster Preparation: A Socio-Technical Systems Perspective. Annals of Operations Research, 283(1), 1259-1282. 
Kotler, P., \& Armstrong, G. (2012). Prinsip-Prinsip Pemasaran. Jakarta: Erlangga.

Kotler, P., \& Keller, K. L. (2016). Manajemen Pemasaran, Edisi 12 Jilid 1 \& 2. Jakarta: PT. Indeks.

Kotler, P., \& Keller, K. L. (2016). Marketing Management. England: Pearson Education Limited.

Lang, M., Wiesche, M., \& Krcmar, H. (2016). What are the Most Important Criteria for Cloud Service Provider Selection? A Delphi Study European Conference on Information Systems (ECIS), 24(119): 1-17.

Maulana, A.D. (2016). Pengaruh Kualitas Pelayanan dan Harga Terhadap Kepuasan Pelanggan PT. TOI. Jurnal Ekonomi. 7(2): 113-125.

McCarthy, E. J. (2008). Pemasaran Dasar Pendekatan Manajemen Global. Jakarta: Salemba Empat.

Millan, C., dan Bartrina, F. (2013). The Routledge Handbook of Translation Studies. New York: Routledge.

Nurhayati. (2017). Belanja "Online" Sebagai Cara Belanja di Kalangan Mahasiswa (Studi Kajian Budaya di Universitas Malikussaleh, Lhokseumawe, Aceh). Aceh Anthropological Journal. 4(2): 1-22.

Park, D., \& Krishnan, H. A. (2001). Supplier Selection Practices aMong Small Firms in the United States: Testing three Models. Journal of Small Business Management, 39(3), 259-271.

Prabowo, H., \& Yulianeu. (2017). Analisis Pengaruh Persepsi Harga, Kualitas Produk dan Kualitas Pelayanan terhadap Kepercayaan Pelanggan dengan Keputusan Pembelian sebagai Variabel Intervening (Studi pada Rumah Fotografi Kudus). Journal of Management. 3(3).

Putri, R. B., Andayani, S., \& Mulyati, A. (2016). Analisis Pengaruh Kualitas Pelayanan Jasa Terhadap Keputusan Pelanggan Pada Studio Foto Fotokita. Jurnal Dinamika Administrasi Bisnis,, 2(2): $1-19$.

Setiadi, N. J. (2010). Perilaku Konsumen. Cetakan 4. Edisi Revisi. Jakarta: Kencana

Santoso, S. (2015). SPSS 20 Pengolahan Data Statistik di Era Informasi, Jakarta: PT. Alex Media Komputindo, Kelompok Gramedia.

Simamora, B. (2011). Memenangkan Pasar dengan Pemasaran Efektif dan Profitabel. Jakarta: PT Gramedia Pustaka Utama.

Soedjono, S. (2006). Pot-Pourri fotografi. Jakarta: Universitas Trisakti.

Soelarko, R.M. (2007). Penuntun Fotografi, Edisi V. Bandung: PT. Karya Nusantara.

Stanton, W.J. (2006). Dasar-dasar Manajemen. Jakarta : Mandar Maju

Tjiptono, F. (2014). Pemasaran Jasa. Yogyakarta: ANDI.

Tjiptono, F. (2015). Strategi Pemasaran, Edisi 4. Yogyakarta: Andi Offset.

Xin L, Mengyue W., Yubo C. (2014). The Impact of Product Photo on Online Consumer Purchase Intention: an Image-Processing Enambled Empirical Study. Proceedings-Pacific Asia Conference on Information Systems (PACIS). 1-14 
Widya Ayu Dyah Astuti \& Sanaji. Atribut-Atribut yang Menjadi Bahan Pertimbangan Pelanggan untuk Memilih Jasa Foto Katalog Produk (Studi pada Pengusaha Online Shop)

Yu, J., Subramanian, N., Ning, K., \& Edwards, D. (2015). Product Delivery Service Provider Selection and Customer Satisfaction in the Era of Internet of Things: A Chinese E-Retailers' Perspective. International Journal of Production Economics, 159(1): 104-116.

Zeithaml, V. A. (2000). Delivering Quality Service. New York: The Free Press.

Zhang, X., Li, Z., \& Wang, Y. (2020). A Review of the Criteria and Methods of Reverse Logistics Supplier Selection. Processes, 8(705). 